\title{
Alternative breeding processes: at which extent Participatory Breeding should modify the concept of ideotypes in plant breeding?
}

\author{
Patrick Vincourt ${ }^{1,{ }^{*}, \mathrm{a}}$ and Pierre Carolo ${ }^{2, \mathrm{~b}}$ \\ ${ }^{1}$ National Institute for Agronomic Research (INRA), Toulouse, France \\ ${ }^{2}$ Corn Research at Euralis Semences, Lescar, France
}

Received 2 July 2018 - Accepted 26 October 2018

\begin{abstract}
The Participatory Plant Breeding (PPB) concept emerged twenty years ago, particularly with the aim to build alternative organizations of the plant breeding activities in developing countries. It now as well questions the developed countries, in the frame of a more global expectation to make all the stakeholders more involved in the agricultural production, from the farmers to its final clients. We discuss here some of the questions addressed by this trend with regard to the definition of the ideotype: (a) different forms of PPB? (b) changing the paradigm: Client Oriented Breeding? (c) a new way to manage \{genotype* environment\} interactions? (d) mainly societal concerns at stake? (e) biodiversity and ideotypes. As the same key, technical, limiting factors are involved in both PPB and classical breeding, it is suggested to consider PPB as one of the ways in the frame of a general expectation for diversification, thus eventually resulting in the promotion of alternative ideotypes, rather than an alternative process.
\end{abstract}

Keywords: participatory breeding / ideotype / $\mathrm{G}^{*} \mathrm{E}$ interaction / stakeholders / bioversity

Résumé - Processus de sélection alternatifs : dans quelle mesure la Sélection Participative devraitelle modifier le concept d'idéotype en amélioration des plantes? Le concept de sélection participative (SP) a émergé il y a vingt ans, particulièrement dans l'objectif de mettre en place des organisations alternatives pour les activités d'amélioration des plantes dans les pays en voie de développement. Maintenant, il interroge également les pays développés, dans le cadre d'une attente plus large de rendre toutes les parties prenantes davantage impliquées dans la production agricole, des agriculteurs à ses clients finaux. Nous discutons certaines des questions posées par cette tendance en ce qui concerne la définition de l'idéotype : (a) différentes formes de SP ? (b) changer de paradigme : sélection orientée « clients »? (c) une nouvelle façon de gérer les interactions \{génotype * environnement\}? (d) les préoccupations sociétales en jeu, principalement? (e) biodiversité et idéotypes. Du fait que les mêmes facteurs clefs limitant sont impliqués dans le cadre de la SP et de la sélection classique, il est suggéré de considérer la SP comme une des voies à emprunter pour répondre à l'attente de diversification, qui se traduira éventuellement par la promotion d'idéotypes alternatifs, plutôt que comme un processus alternatif.

Mots clés : sélection participative / ideotype / interaction $\mathrm{G}^{*} \mathrm{E} /$ parties prenantes / biodiversité

\section{Introduction}

The concept of agroecology was initially aiming at including the scientific and technical aspects of ecology in

\footnotetext{
*Correspondence: patrick. vincourt@orange.fr

a Retired from National Institute for Agronomic Research (INRA), Toulouse, France.

${ }^{\mathrm{b}}$ Now retired. Formerly Head of Corn Research at Euralis Semences. Present address: 14 rue d'Azé, 41100 Vendome, France.
}

the global process of agriculture. However, as pointed out in a recent report from the Joined Ethical Committee from INRA, CIRAD and IFREMER (Advice 11, 2018), it progressively moved towards accounting for social sciences, i.e. the need to associate a wider range of stakeholders, including consumers and farmers, in the definition of the objectives, methods and technologies of agricultural activities. At the same time, the growing interest for biodiversity as a key resource to make possible the adaptation of human needs in a rapidly evolving world reinforced the point of view considering that any cultivar should intrinsically contain enough genetic variability to 


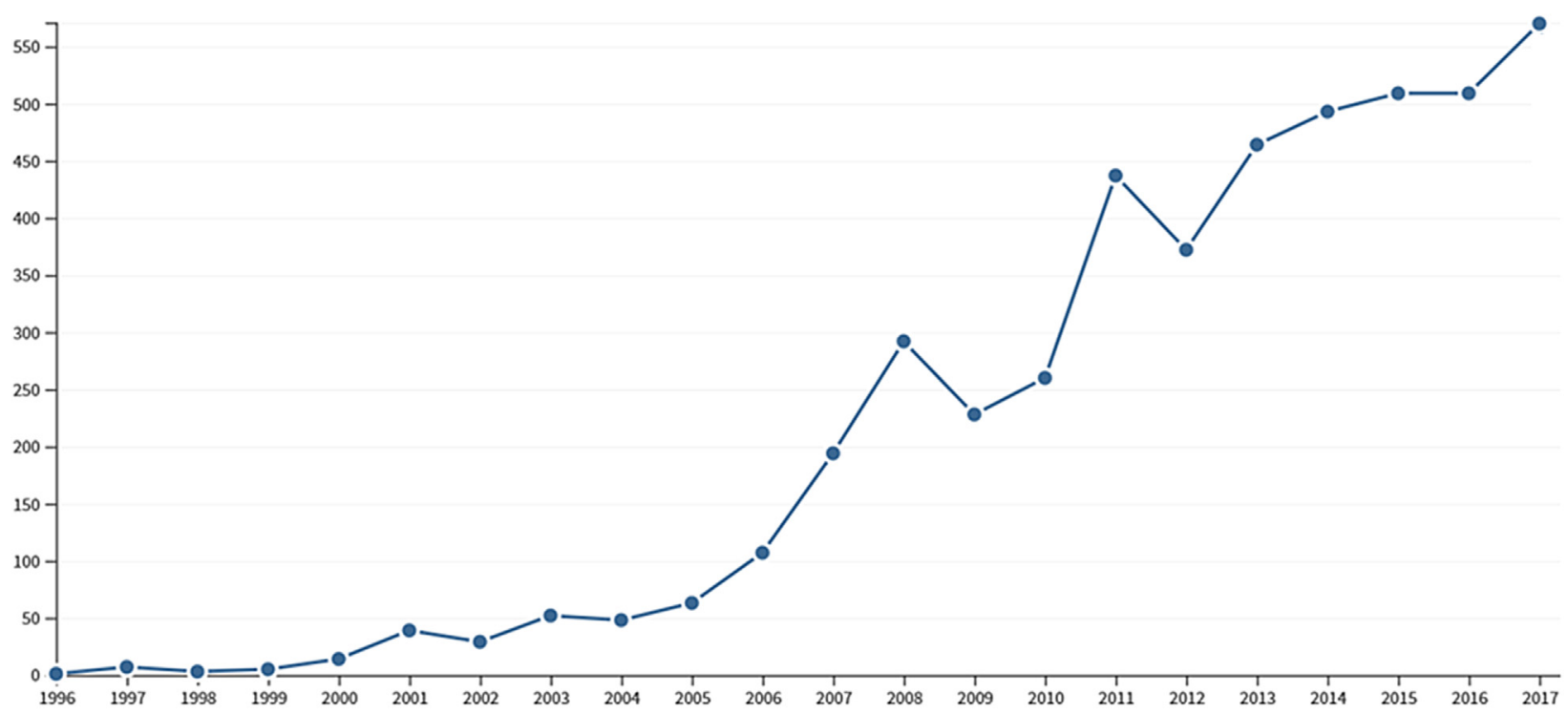

Fig. 1. Rapid growth of citations for scientific articles having \{participatory + breeding\} in their topic. Source: Web of Science (May 18, 2018); Total of 420 publications.

evolve. These two trends, together with political considerations which will be not discussed here, resulted in the emergence of experimental and theoretical approaches dedicated to Participatory Plant Breeding (PPB). As illustrated by the previous articles contributing in the review, the definition of ideotypes corresponding to the diversification of the needs remains a challenge, even when the targeted genotype is a genetically homogenous variety, like pure line or hybrid. After Desclaux et al. (2013), this article addresses the question whether PPB approaches should modify, enrich, or even make irrelevant the concept of ideotype in plant breeding.

\section{What "Participatory Breeding" is the name for?}

During the last twenty years, more and more attention has been paid by researchers on Participatory Breeding (Fig. 1). However, it appears that behind this concept, quite different approaches have been developed.

Some of them are using the "Target Population of Environments" (TPE, See Gauffreteau, in this review) actually provided by a set of participating farmers to implement the same type of process the seed industry is using ("Classical Breeding", CB). As an example, the use of a global statistical model to analyze the data (Rivière et al., 2015) imposes to make common the ways of phenotypic evaluation as well as the rules of ranking: any formalized or non-formalized selection index. Another example is provided by the partnership between farmers and private companies in the Dutch potato breeding model (Almekinders et al., 2014), where "Through farmers' participation, the company breeders can handle many more crossings and seedlings, without having to evaluate all seedlings themselves". In some other cases, the main goal is, while motivating the farmers in such process, to provide a particular landrace with a protected denomination, indication, or status which is clearly associated with an ideotype (ex.: Hurtado et al., 2014, for the Almagro pickling eggplant; see also Alves et al., 2017, for broa, a local Portuguese maize-based bread); but basically, such approach finally results in a quite classical breeding program. In such implementations of the PPB concept, the participant farmers are essentially playing their role as workers, like in a vertical, classical breeding organization.

However, a strong trend in PPB approaches is aiming to face more closely the breeding process with the genotype * environment $*$ cropping practices $\}(\mathrm{G} * \mathrm{E} * \mathrm{C}$ interaction), with the assumption that local (environment + farmers pratices) selection is more efficient than global selection to provide farmers, and thereafter consumers, with sustainable genotypes, "sustainable" being mainly understood as (1) providing all the farmers with a sustainable income, (2) preserving the environment, and (3) providing the consumers with healthy products. Frequently, there is also a second underlying hypothesis - at least in the professions of faith disseminated through the Web: the genetic heterogeneity of cultivars, like local/ancestral populations, should be maintained, not only as genetic resources to be preserved in dedicated organizations, but as such, in order to ensure the crop sustainability and evolvability. As far as the range of genetic variability in such heterogeneous cultivars is not defined, would the concept of ideotype be still relevant?

\section{Changing the paradigm: "Client Oriented Breeding" (COB)?}

As a basis to distinguish the different forms of plant breeding (either PPB or "conventional"), it has been proposed (Witcombe et al., 2005, 2006; Joshi et al., 2007; Virk and Witcombe, 2007; Witcombe and Yadavendra, 2014) to use the "degree of client orientation". Witcombe et al. (2005) pointed out that "it is better not to use any qualitative label that implies a dichotomy among breeding programmes, e.g. participatory 
or conventional", and they rather proposed to use a "quantitative description of the degree of client orientation". Among the criteria these authors suggested to take into account to reflect such degree, there is (1) a choice of germplasms involved as genetic resources in the first steps of the breeding program, according to their specific adaptations to (2) target environments. The underlying assumption is therefore that the experience the stakeholders involved in cultivar evaluation (farmers, but also extension services or non-governmental organizations) have regarding the adaptation of cultivars is strong enough to provide relevant information for a more pertinent choice of such germplasms as sources to develop more promising segregating populations. The authors also suggested that the discrepancy between traditional "selection environments" (SE) - with generally high inputs (water, fertilizers, pesticides) - and TPE impairs the selection pressure and results in poor actual selection efficiency.

At this point, some comments need to be done. Firstly, it is not so sure that the specific adaptation of a cultivar to a particular TPE is easy to demonstrate, except after several years of testing. There are plenty of cases in the plant breeding history where after ten years of selection, a genotype seeming to be highly promising is finally defeated by an unpredicted susceptibility to a stress. Reducing the genetic variability involved in the breeding process to the quite low range of "known" cultivars ("few-cross strategy", Witcombe et al., 2005) might therefore be too conservative. It may also result in the characterization of an ideotype on the renown of a small set of cultivars (sometimes, highly related), without any comparative, experimental basis. Secondly, while it's true that $\mathrm{SE}$ does not provide the best information regarding the genotypic responses to several biotic or abiotic stresses, it remains also true that non-SE trials alone do not provide - except, often by chance, in some $\{\mathrm{G} * \mathrm{E} * \mathrm{C}\}$ combinations relevant data for further statistical analysis, just because of the magnitude of experimental error. Thirdly, the PPB approaches were initially developed with the aim to provide the farmers from developing countries with cultivars more adapted to cultivation and local needs for food, than varieties provided from outside and often by seed companies. In this case, even when technical properties of the harvest (grain quality, etc.) are also considered, the clients are here essentially the farmers and the final consumers. In developed countries, the clients are mainly the food and retailing industries, which has some particular requirements and which, whether good or bad, imposes at least some components of the ideotype.

\section{Managing $G * E * C$ interactions}

Altogether, the questions raised by the PPB approaches converge, for their technical aspects, towards better taking into account the $\left\{G^{*} E * C\right\}$ interactions in the breeding process, while integrating a wider range of stakeholders (ex.: participating farmers) in the global process. Genotypes, environments (resulting from location* year combinations) and cropping systems are clearly interacting. Desclaux et al. (2008) stated that "The standardization of environments (E) encouraged by modern society and by the productivist model of agriculture has resulted in the standardization of genotypes (G) thereby reducing $\mathrm{G}^{*} \mathrm{E}$ interaction". However, when considering the effects of the different sources of variation in crop experimentation, some of them are more predictable and/ or of greater impact than others. For example, except for some resistances to diseases, the differences between genotypes are generally much lower than the differences between \{environments * cropping systems $\}$ combinations, including for quality traits. When trying to rank the predictable size of the different effects from scientific publications (ex.: González-Barrios et al., 2017 for sunflower) or from practical experiences in field testing, it appears that (1) the average genotypic effect is intrinsically the most stable - this is the essence of broad sense heritability, (2) the location effect is quite stable and high, but interacting strongly with the year of cultivation, (3) there are strong variations from one year to another, being understood that the year effect is expected to grow because of the climate change. At the end of the story, the possibility to ensure that a particular genotype is adapted to a particular $\left\{\mathrm{E}^{*} \mathrm{C}\right\}$ combination seems to be poor, compared with the assessment of its ability to be enough adapted to a wide range of environments. A comparison could be made with the "Combining Ability" in hybrid breeding: when well organized, taking care of the General Combining Ability (GCA, i.e. the main effect of parental lines in hybrid breeding) is efficient enough, at least during the first steps of the breeding process. Of course, there are some famous exceptions, resulting in the identification of particular, highly successful hybrid combinations, but the economy of the breeding process would not have given the chance to identify them through a perfect, rational system. Here we argue that the same challenge is encountered for $\left\{\mathrm{G}^{*} \mathrm{E} * \mathrm{C}\right\}$ interactions. Regardless the way the breeding process is organized, it would be always more difficult to assess the specific adaptation of a cultivar to a particular "terroir" than to identify a more widely adapted cultivar. We therefore question at which conditions a local selection could be more efficient than global selection to reach the goal of local adaptation (Supplementary Material). Furthermore, even when $\left\{G^{*} E * C\right\}$ interactions are present thus resulting in quite poor positive correlations between locations, the information collected in one location can be used to infer the genotypic value in another location (Vincourt and Gallais, 1983, Vincourt et al., 1984). Therefore, what is at stake regarding the technical aspects of PPB is how strong should be the level of cooperation between the involved actors. Indeed, any observation on the crop response in any location could be of interest for any particular stakeholder.

\section{What is really at stake comes from societal concerns}

Enlarging the range of the clients (COB strategy) in the breeding process does not reflect enough the PPB movement. What is at stake is not the range of the clients, but the way these actors are implicated in the process. In other words, the paradigm shift is not really of technical nature, but aims at involving the field of social sciences. In a very clear case study (mungbean in Nepal), Joshi et al. (2014) argue that the classical regulatory aspects of the seed system impairs the speed of diffusion of the genetic innovations, when compared to the implication of an "Informal Research and Development" community deeply related with the PPB approach. However, 
one might suspect that the difficulty here is actually connected with the fact that, as for human diseases, there are some orphan threats for which neither the seed industry nor the governmental organizations are taking charge. It is therefore more on the social aspects than on the technical aspects of the breeding process that the PPB approach is able to bring solutions. Kidane et al. (2017) identified in durum wheat and by a GWA study, QTL associated with smallholder farmer preferred traits (PPB approach) and with classical metric traits. The authors concluded that "smallholder farmers' traditional knowledge can yield QTL eluding metric measurements of phenotypes". While this publication is highly documented in terms of experimental design and statistical analysis, one might have some criticisms on the conclusions. The empirical ("overall") evaluation of the farmers and the grain yield (metric trait) are significantly correlated (from $\mathrm{r}=0.32-0.53$, i.e. $\mathrm{r}^{2}$ from $0.10-0.26 \%$, for a panel of 400 accessions). But the prediction ability remains low, and considering that it would be of interest to "elude" metric traits would mean that the target of PPB is clearly elsewhere than a better global efficiency. The aim is preferentially to better make sense for the main stakeholders in the agricultural production. Therefore, the question is no longer if a cultivar fits with a technical ideotype, but if it fits with the profile a given community of stakeholders is comfortable with. Throughout the PPB literature, the process by which the innovation brought by a cultivar is adopted (ex.: Ceccarelli, 2015) has been pointed out as a key limiting factor of breeding efficiency. This might result in a high diversification of breeding targets and ideotypes. Some of them would be targeted through a PPB approach (for example, those associated with organic agriculture: more aggressiveness towards weeds, more phenotypic variability in flowering time, etc.), because the main limiting factor is the adoption by a farmers or a consumer's community. Some others would be addressed through classical procedures, for example when the purpose is to give an efficient and fast genetic answer regarding an emerging pathogenic threat.

\section{Biodiversity and ideotypes}

Among the trends in force within the PPB movement - at least in the perception the public media are cultivating -, there is the faith that the genetic homogeneity of cultivars (pure lines for autogamous crops or hybrids for allogamous crops) is (1) impairing the evolvability of the cultivar - what is true-, (2) limiting the actual adaptation of the cultivar across a wide range of $\left\{\mathrm{G}^{*} \mathrm{E}\right\}$ combinations, (3) impairing the preservation of the biodiversity, and (4) creating the conditions for an economic dependency of the food chain towards oligopolies. The last argument will be kept outside of the discussion in the frame of this paper. Regarding the second argument, it is often argued that genetic heterogeneity results, in itself, in a better adaptation to a wide set of environments. However, this assumption is not well documented. Lana et al. (2017) compared, using the CERES-maize crop model, the response to the climate (30 years of data in Brazil locations) and planting dates of four maize cultivars: a commercial hybrid, and three open-pollinated cultivars, resulting (cultivar MPA01) or not from an integrated PPB approach. They concluded that MPA01 is more adapted to diverse $\left\{G^{*} \mathrm{E}\right\}$ combinations than the commercial hybrid AS1548. However, the development cycles of these two cultivars are quite different (table 1 in Lana et al., 2017), and this might obviously impair any general conclusion, as the development cycle is known to have a strong effect on $\{G * E\}$ interactions. Interestingly, one of the four tested cultivars (Ivanir) resulted from an empirical mixture of several varieties, and was too much genetically variable to be considered in the study.

Forty years after (Marshall and Pryor, 1979), the concept of multiline varieties is back. The purpose here is to face the population of pathogens with a more diverse pattern of resistance genes than usual, in order to limit the emergence of virulence pathotypes - and, as a consequence, to accept a "dirty crop". For sunflower, Tourvieille de Labrouhe et al. (2005) found that stacking different $P l$ genes for resistance to $P$. halstedii (downy mildew) is at least as efficient as a mixture (i.e. multiline), for the short term (4 years). However, they pointed out that such result is highly depending on the biology of the \{plant* pathogen interaction. In other words, defining an ideotype when it's needed to account for \{plant* pathogen\} interaction - and certainly for \{plant* plant \} interaction, like in mixtures of species - remains a difficult, and quite poorly documented, challenge. We raise therefore the question whether the genetic heterogeneity of a cultivar (synthetic varieties, mixtures of lines or even species, populations under recurrent selection, etc.) hinders the definition of an ideotype. Theoretically, it doesn't. However, defining an ideotype is also defining a set of constraints, which leads to apply a selection pressure. Therefore, giving an intrinsic value to the genetic diversity of a cultivar does make sense if the purpose is to maintain the biodiversity, but doesn't make sense if the purpose is to define the rules and ways to define the adaptation of a cultivar and of its use to a particular environment. Of course, it would be theoretically possible to precise, regarding a cultivar, which traits should retain a part of the genetic variability for its adaptation, and which traits should not, in order to fit with an ideotype. However, as far as interactions with the environment (either abiotic or biotic) are concerned, it's already difficult to describe such interactions for a homogeneous cultivar.

In the PPB literature, the Distinction - Uniformity - Stability (D.U.S) concept in use within the organizations in charge of regulating the innovation flow between the plant breeding research and its clients is often considered as a threat towards the speed of innovation flow. Actually, D.U.S. was initially devoted to protect the "clients" (farmers to final consumers), and not only the innovators from the seed industry. In the non-agricultural industry, a clear definition of what is the product is more and more required. While, in developed countries, the public opinion is also requiring more and more information about the food (what? how? where?), there is at least an apparent, strong contradiction with the expressed requirement to access to poorly characterized food sources. How to deal with a resource which is not enough described (ex.: response of the genotypic profile to the environment in terms of resistance to diseases, nutritional and industrial functionalities of the harvest) over the whole \{farmers $->$ final consumers $\}$ agricultural workflow?

\section{Discussion and conclusion}

Depending on the crop, for which final end user, and where (ex.: local, human consumption vs. integration in the food or 
energy or basic material chain), the concept of ideotype as well as the PPB approach do not have the same implication, and application. Considering the technical side, PPB and classical plant breeding methods do not differ so much. Indeed, the same limiting factors (genetic variability, as the primary source, and ability to phenotype a large range of $\left\{G^{*} E\right\}$ combinations) are involved in both cases. However, the Report of the European Community FOOD 2030 Independent Expert Group (2018) pointed out, among four priorities, the link between "innovation and empowerment of communities", and that "the transformation of the food system should make it more sustainable, resilient, responsible, diverse (i.e. "being open to a wide range of technologies, practices, approaches, cultures and business models"), competitive and inclusive (i.e. "engaging everyone involved in the food system, plus civil society, fighting food poverty, and providing healthy food for all")". Some start-ups have been launched with the aims to develop "personalized seeds" (ex: http://agwired.com/2018/07/18/ inari-aims-to-transform-agriculture/), thus following the same trend than "personalized medicine". When discussing about risks and opportunities, the TYFA project (Ten Years For Agroecology in Europe, https://www.iddri.org/fr/publicationset-evenements/billet-de-blog/une-europe-agroecologique-en2050-un-scenario-credible-un) is also considering "regionalized breeding" as a solution to mitigate the yield gap (today, about $30 \%$, with high variations depending on the crop and the environment) between conventional and organic crop production. While it's difficult to predict whether this trend towards "local" approaches would result or not in better results for overall people health and in better efficiency in the R\&D process is still highly questionable. At the same time, even if a better involvement of a wider range of stakeholders is needed to improve the interaction between plant breeding science and society, it remains of upmost importance to share common facts and rules, as well as to share questions.

Which place should take the biodiversity - and which type of biodiversity? - in the game of the plant breeding is not so clear. Should the biodiversity be just a museum? No, for sure. At which extent the genetic homogeneity (lines or hybrids) of a wide range of cultivars is by itself adverse towards the evolvability/adaptability of crops for future human needs? Today, the facts are that, in France as well as in others countries, together with public research institutions and technical institutes, the seed industry is clearly involved in the preservation and the characterization (including molecular diversity) of such biological resources. Therefore, would it be better to invest with all the stakeholders in the characterization of these resources - even if some of these stakeholders express some contradictory needs -, rather than to expect that "local" approaches would provide us with the best solution in any case?

Because the PPB approach could be, mainly as an hypothesis, able to fulfill a wider range of needs, including the societal ones, it can be considered as a sting for conventional breeding, as well as the methods involved in conventional breeding could be (and actually, already are) integrated in PPB to make it more effective. It should be considered that, rather than expressing a strong alternative way in the plant breeding process, the PPB approach has to be considered as accounting for the general trend towards the diversification of needs and clients - and consequently, of the ideotypes delivered to them.

\section{Supplementary Material}

Predicting the adaptation of a genotype to a particular environment.

The Supplementary Material is available at https://www.ocljournal.org/10.1051/ocl/2018061/olm.

Acknowledgments. The authors thank J.M. Nolot (agronomist, formerly head of INRA Occitanie Toulouse of Auzeville Unit of Plant Breeding Experimentation, for controversial and fruitful discussions.

\section{References}

Almekinders CJM, Mertens L, van Loon JP, Lammerts van Bueren ET. 2014. Potato breeding in the Netherlands: a successful participatory model with collaboration between farmers and commercial breeders. Food Sec 6: 515-524.

Alves ML, Brites C, Paulo M, et al. 2017. Setting up decision-making tools toward a quality-oriented participatory maize breeding program. Front Plant Sci 8: 2203.

Ceccarelli S. 2015. Efficiency of plant breeding. Crop Sci 55(1): 87-97.

Desclaux D, Nolot JM, Chiffoleau Y, Gozé E, Leclerc C. 2008. Changes in the concept of genotype 3 environment interactions to fit agriculture diversification and decentralized participatory plant breeding: pluridisciplinary point of view. Euphytica 163: 533-546.

Desclaux D, Chiffoleau Y, Nolot JM. 2013. Du concept d'Ideotype à celui de Realtype : gestion dynamique des innovations variétales par une approche transdisciplinaire et partenariale. Exemple du blé dur pour l'AB. Innov Agron, INRA 32: 455-466.

González-Barrios P, Castro M, Pérez O, Vilaró D, Gutiérrez L. 2017. Genotype by environment interaction in sunflower (Helianthus annus L.) to optimize trial network efficiency. Span J Agric Res 15 (4): e0705.

Hurtado M, Vilanova S, Plazas M, et al. 2014. Enhancing conservation and use of local vegetable landraces: the Almagro eggplant (Solanum melongena L.) case study. Genet Resour Crop Evol 61: 787-795.

Joined Ethical Committee from INRA, CIRAD and IFREMER. 2018. Avis 11 sur «Les nouvelles techniques d'amélioration génétique des plantes» (in French). Available at http://plateforme-documen taire.ctifl.fr/Record.htm?record=19522016124913402989 (last consult: 2018/06/17).

Joshi KD, Musa AM, Johansen C, Gyawali S, Harris D, Witcombe JR. 2007. Highly client-oriented breeding, using local preferences and selection, produces widely adapted rice varieties. Field Crops Res 100: 107-116.

Joshi KD, Khanal NP, Harris D, et al. 2014. Regulatory reform of seed systems: Benefits and impacts from a mungbean case study in Nepal. Field Crops Res 158: 15-23.

Kidane YG, Mancini C, Mengistu DK, et al. 2017. Genome wide association study to identify the genetic base of smallholder farmer preferences of durum wheat traits. Front Plant Sci 8: 1230.

Lana MA, Eulenstein F, Schlindwein SL, Graef F, Sieber S, von Hertwig Bittencourt H. 2017. Yield stability and lower susceptibility to abiotic stresses of improved open-pollinated and hybrid maize cultivars. Agron Sustain Dev 37: 30. 
Marshall DR, Pryor AF. 1979. Multiline varieties and disease control. II. The "Dirty Crop" approach with components carrying two or more genes for resistance. Euphytica 28: 145-159.

Report of the EC FOOD 2030 Independent Expert Group. 2018. Recipe for change: An agenda for a climate-smart and sustainable food system for a healthy Europe. Executive summary. Available at https://ec.europa.eu/research/bioeconomy/pdf/publications/ ES_recipe_for_change.pdf (Last consult: 2018/06/17).

Rivière P, Dawson JC, Goldringer I, David O. 2015. Hierarchical Bayesian modeling for flexible experiments in decentralized participatory plant breeding. Crop Sci 55: 1053-1067.

Tourvieille de Labrouhe D, Mestries E, Walser P. 2005. Quelles perspectives pour la lutte génétique vis-à-vis du mildiou du tournesol? OCL 12(2): 85-93.

Vincourt P, Gallais A. 1983. Sur la recherche de critères de sélection : la régression géno phénotypique. Agronomie 3(9): 827-830.
Vincourt P, Derieux M, Gallais A. 1984. Quelques méthodes de choix des génotypes à partir d'essais multilocaux. Agronomie 4(9): 843-848.

Virk DS, Witcombe JR. 2007. Trade-offs between on-farm varietal diversity and highly client-oriented breeding - a case study of upland rice in India. Genet Resour Crop Evol 54: 823-835.

Witcombe JR, Yadavendra JP. 2014. How much evidence is needed before client-oriented breeding (COB) is institutionalised? Evidence from rice and maize in India. Field Crops Res 167: 143-152.

Witcombe JR, Joshi KD, Gyawali S, et al. 2005. Participatory plant breeding is better described as highly client-oriented plant breeding. I. Four indicators of client-orientation in plant breeding. Expl Agric 41: 299-319.

Witcombe JR, Gyawali S, Sunwar S, Sthapit BR, Joshi KD. 2006. Participatory plant breeding is better described as highly clientoriented plant breeding. II. Optional farmer collaboration in the segregating generations. Expl Agric 42(1): 79-90.

Cite this article as: Vincourt P, Carolo P. 2018. Alternative breeding processes: at which extent Participatory Breeding should modify the concept of ideotypes in plant breeding? OCL 25(6): D606. 